-Note-

\title{
The effect of administration of fenbendazole on the microbial hindgut population of the horse
}

\author{
Laura CROTGH-HARVEY ${ }^{1,2}$, Leigh-Anne THOMAS ${ }^{1}$, Hilary J. WORGAN ${ }^{1}$, \\ Jamie-Leigh DOUGLAS ${ }^{1}$, Diane E. GILBY ${ }^{2}$ and Neil R. MGEWAN ${ }^{1,3 *}$ \\ ${ }^{1}$ Institute of Biological, Environmental and Rural Sciences, Edward Llwyd Building, Penglais Campus, Aberystwyth \\ University, SY23 3DA, Wales, U.K. \\ ${ }^{2}$ Equine, Pets and Livestock Animalcare, Glien House, Glien Road, Cillefwr Industrial Estate, SA31 3RB, Wales, U.K. \\ ${ }^{3}$ School of Pharmacy and Life Sciences, Robert Gordon University, AB10 7GJ, Scotland, U.K.
}

\begin{abstract}
Anthelmintics are used as anti-worming agents. Although known to affect their target organisms, nothing has been published regarding their effect on other digestive tract organisms or on metabolites produced by them. The current work investigated effects of fenbendazole, a benzimidazole anthelmintic, on bacteria and ciliates in the equine digestive tract and on and their major metabolites. Animals receiving anthelmintic treatment had high faecal egg counts relative to controls. Analysis was performed over two weeks, with temporal differences detected in bacterial populations but with no other significant differences detected. This suggests fenbendazole has no detectable effect on organisms other than its targets. Moreover it does not appear to make a contribution to changing the resulting metabolome.
\end{abstract}

Key words: bacterial profile, horse, metabolome, worming

\author{
J. Equine Sci. \\ Vol. 29, No. 2 \\ pp. $47-51,2018$
}

One of the major sources of digestive problems in horses results from worm infection, particularly parasitic helminths which inhabit the caecum and colon in the hindgut. These worms produce eggs which are shed in the faeces of infected animals. By collecting faeces from animals and performing a faecal egg count (FEC), it is possible to gain an approximation of an animal's extent of infection [7]. The extent of infection can vary greatly over time [12].

Treatment of intestinal worms in horses is normally carried out by dosing with anthelmintics. In horses there are three classes of anthelmintics used commercially, macrocyclic lactone (ML), benzimidazoles (BZs), and tetrahydropyrimidines (THPs), with widespread resistance to drugs in each category [10], including non-domesticated animals [2]. Reasons for resistance probably include: underdosing of animals [8]; overuse of wormers [8]; and blanket approaches to anthelmintic treatments [6].

Received: January 16, 2018

Accepted: April 27, 2018

*Corresponding author. e-mail: n.mcewan@rgu.ac.uk

(C)2018 Japanese Society of Equine Science

This is an open-access article distributed under the terms of the Creative Commons Attribution Non-Commercial No Derivatives (by-nc-nd) License. (CC-BY-NC-ND 4.0: https://creativecommons.org/licenses/ by-nc-nd/4.0/)
Even horses with low FEC values may be a potential infection source within the wider population [11]. Based on the FEC value of individuals it is possible to treat only those on a site with high counts, although evidence suggests that this is not done routinely [9], despite suggestions that this approach can involve spending significantly less money on anthelmintics [1], as previous worming routines [4] continue to be used.

Although anthelmintics are assumed to specifically target worms of the digestive tract, it is unclear what the secondary effects on the microbial population of the digestive tract are likely to be following dosing with a wormer. The current work investigates this deficiency in knowledge by looking at the effect of treatment with fenbendazole on gut bacterial and ciliate populations, as well as the major metabolites, in animals which either received anthelmintic treatment relative to controls. Here we use Terminal Restriction Fragment Length Polymorphism (T-RFLP) as a means of evaluating the microbiome of faecal samples and Fourier Transformed Infrared (FT-IR) spectroscopy to study bonds present in faecal samples as a means of indicating metabolites present.

Faecal samples were collected from horses on pasture in a single field on 9, 11, and 23 June 2012. Where the FEC was $>200$ eggs per gram of faecal matter, horses were treated with anthelmintics, whilst those with values below this were 
not treated (control animals). Treatment was with Panacur (Intervet, Milton Keynes, U.K.) paste (fenbendazole $7.5 \mathrm{mg} /$ $\mathrm{kg}$ ) and followed the manufacturer's recommendations. Five control (A-E) and five treated (F-J) animals were studied as part of the routine treatment process.

On the day of worming (day 0) a fresh faecal sample was collected from each animal. Only after faecal samples had been collected did worming, if required, take place. Fresh faeces were collected, as a representation samples which had recently been in the horse's hindgut, and samples were frozen until ready for either DNA analysis to investigate microbial populations or FT-IR analysis to investigate metabolite profiles. In addition, $1 \mathrm{~g}$ was placed in a tube containing $12 \mathrm{ml}$ of $4 \%(\mathrm{w} / \mathrm{v})$ formalin in $0.9 \%(\mathrm{w} / \mathrm{v})$ sodium chloride to fix ciliated protozoa present in samples. Further faecal samples were collected from animals 2 and 14 days later.

A drop of methylene blue stain (0.5 g Methylene Blue, $2 \mathrm{~m} l$ of acetic acid, $100 \mathrm{~m} l$ of $\mathrm{dH}_{2} \mathrm{O}$ ) was added into each fixed protozoal sample. After mixing they were left for at least $6 \mathrm{hr}$ to allow protozoa to take up the dye. The number of protozoa in $20 \mu \mathrm{l}$ of solution was determined by microscopy in triplicate.

DNA was extracted as described previously [3]. Frozen samples were freeze-dried for $72 \mathrm{hr}$. Aliquots $(100 \mathrm{mg})$ of each freeze-dried sample were placed in a micro-centrifuge tube with a $4 \mathrm{~mm}$ glass bead. Samples were agitated using a BeadBeater (Biospec Products, Bartlesville, OK, U.S.A.) for 2 min to disrupt cells. DNA extraction was then performed using a stool kit (Qiagen, Manchester, U.K.) according to the manufacturer's recommended protocol, including an initial incubation step at $95^{\circ} \mathrm{C}$, since the samples had a high Gram-positive bacterial concentration. Extracted DNA was resuspended in ultrapure water and quantified using a NanoDrop (ND-1000 spectrophotometer).

PCR was performed for T-RFLP analysis. All reactions were carried out in $25 \mu l$ volumes containing $0.5 \mu \mathrm{M}$ of each primer; 27f cy5 (5'-AGAGTTTGATCCTGGCTCAG-3') and 1389R (5'-ACGGGCGGTGTGTACAAG-3'), with 1.25 $\mathrm{U}$ Taq DNA polymerase (Promega) per reaction. Reactions used the reaction buffer supplied by the manufacturer plus $1.75 \mathrm{mM} \mathrm{MgCl}_{2}$ and $5 \mathrm{mM}$ dNTPs. PCR was performed using a BioRad MyCycler with an initial incubation of $94^{\circ} \mathrm{C}$ at $10 \mathrm{~min} ; 25$ cycles at $94^{\circ} \mathrm{C}$ for $30 \mathrm{sec}, 59^{\circ} \mathrm{C}$ at $30 \mathrm{sec}$, $72^{\circ} \mathrm{C}$ at $1 \mathrm{~min}$; a final cycle at $94^{\circ} \mathrm{C}$ for $1 \mathrm{~min}, 59^{\circ} \mathrm{C}$ for 30 sec, and $72^{\circ} \mathrm{C}$ for $10 \mathrm{~min}$; and then a final hold at $4^{\circ} \mathrm{C}$. The resulting amplicon was examined by electrophoresis with an agarose gel to check for products of the anticipated size (c. 1350 base pairs).

Amplicon concentrations were determined using the NanoDrop (ND-1000 spectrophotometer) and normalised to $17 \mathrm{ng} / \mu l$. Restriction enzyme digestion was performed in a 96-well plate using $5 \mu l$ of DNA solution. All enzymes were from Promega, and reactions carried out in the buffers provided, with $100 \mathrm{U}$ per reaction for HaeIII and $50 \mathrm{U}$ per reaction for $M s p \mathrm{I}$ and $H h a \mathrm{I}$. In all cases reactions were performed in $50 \mu \mathrm{l}$ at $37^{\circ} \mathrm{C}$ for $5 \mathrm{hr}$ and terminated by incubation at $80^{\circ} \mathrm{C}$ for $15 \mathrm{~min}$.

After restriction enzyme digestion the following were added directly to the 96-well plate: $4 \mu l$ of $100 \mathrm{mM}$ EDTA;

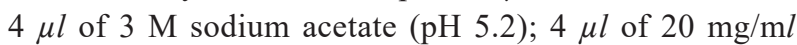
glycogen; and $120 \mu \mathrm{l}$ of $95 \%$ ethanol (pre-chilled to $-80^{\circ} \mathrm{C}$ ). The plate was centrifuged in a Biofuge Primo at 3,000 rpm for $30 \mathrm{~min}$ at $4^{\circ} \mathrm{C}$. The supernatant was removed, $200 \mu \mathrm{l}$ fresh $70 \%$ ethanol (pre-chilled to $-20^{\circ} \mathrm{C}$ ) was added, and the plate was centrifuged as before. Following supernatant removal, $35 \mu l$ of SLS (GenomeLab sample loading solution) buffer was added with $0.2 \mu l$ of DNA size standard (GenomeLab DNA size standard kit 600) and shaken gently for $20 \mathrm{~min}$. All samples were analysed using the T-RFLP setting on a Beckman Coulter CEQ 8000 Genetic Analysis System DNA sequencer.

Frozen faecal samples $(2 \mathrm{~g})$ were measured out, $8 \mathrm{ml}$ of distilled water was added per sample, and the samples were placed into a stomacher for $1 \mathrm{~min}$. An aliquot of each sample was transferred into a $2 \mathrm{~m} l$ tube and freeze-thawed 3 times before $20 \mu l$ (in triplicate) of each sample were pipetted onto an FT-IR plate. The plate was dried overnight at $50^{\circ} \mathrm{C}$ and then analysed by FT-IR using a Vertex 70 spectrophotometer.

Protozoal numbers were analysed by ANOVA to evaluate differences due to sampling dates, wormer status, and datewormer interactions. For each restriction enzyme digestion, peak heights were calibrated to ensure background noise $(<1 \%$ of the tallest peak per sample) was removed. Remaining values were converted to percentages of totals, and data were transformed to fourth root values. Principal Component Analysis (PCA) was carried out to compare samples using MATLAB (R2009a) software.

FT-IR data were also analysed by PCA using MATLAB (R2009a) software.

The daily protozoal numbers for days 0,2 , and 14 were 12,900 (standard error of the mean=4,130), 2,600 (660), and 2,800 (250) in control animals and 4,500 (720), 10,400 $(2,980)$, and $7,600(1,740)$ in treated animals, respectively. No significant differences $(P>0.05)$ were observed between sampling dates, wormer status, or date-wormer interactions.

A plot (Fig. 1) based on the two principal components (PCs) following PCA illustrated that the main variation in the bacterial community was due to temporal variation, with three distinct groups observed: day 0, day 2 and day 14 respectively.

PCA analysis of FT-IR data (Fig. 2) showed that the major PC accounted for $94.1 \%$ of sample variation, whilst 


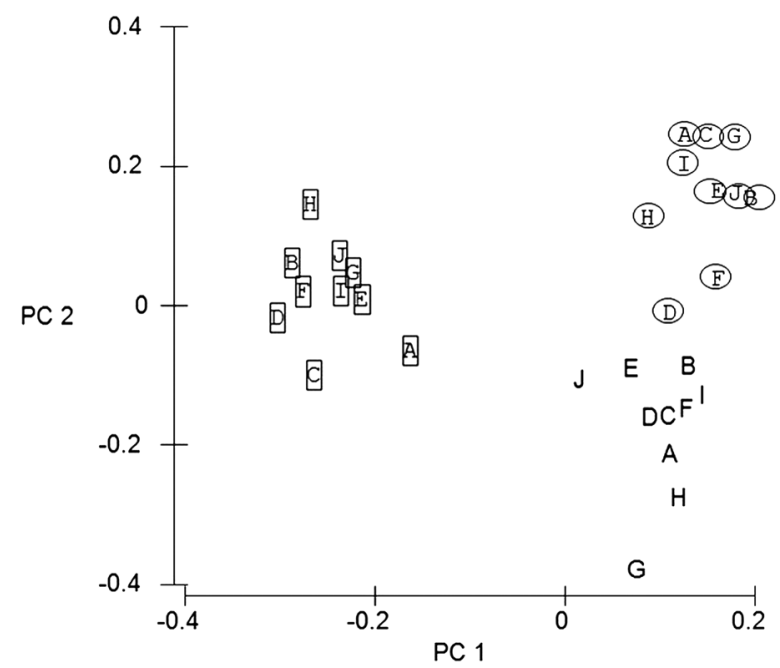

Fig. 1. Principal Component Analysis plot of principal components 1 and 2 from T-RFLP data following fourth root transformation. Samples are distinguished based on day of collection; those collected immediately before worming (day 0 ) are shown without a surrounding circle or square, those collected two days after worming (day 2) are shown in circles, and those collected fourteen days after worming (day 14) are shown in squares. Control animals (no worming treatment) are denoted by the letters A-E, whilst those which were wormed are denoted by the letters F-J. Data appear to cluster based on the date of sampling.

A

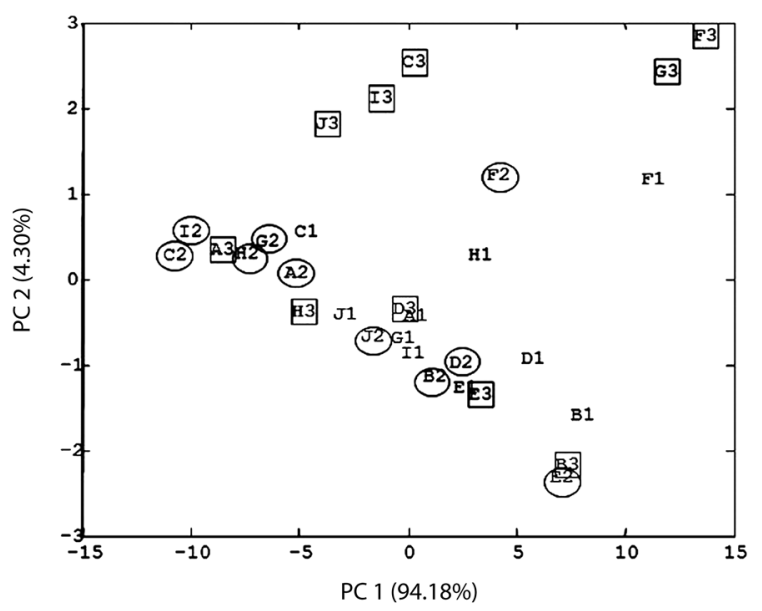

the second one accounted for $4.3 \%$. However, when examined individually against each other, there was no clear split between samples. This is true for either worming regime or date of faecal collection. This indicates that there are no major differences in terms of the major metabolites present.

These results suggest that the worming agent has relatively little impact on the rest of the microbial population of the hindgut-based on faecal samples as a representation of organisms recently present in the animal's digestive tract. This is true for both bacteria (based on T-RFLP profiles) and protozoa.

For protozoa, there was considerable variation between animals, as reflected by the large SEM values. It is worth noting that some of these values were rather low but were still within the range described previously [5]. However there was no significant difference observed in the protozoal numbers either between sampling dates or between control animals versus those treated with fenbendazole.

For bacterial samples, there was evidence of a temporal split (Fig. 1), with T-RFLP data segregating based on sampling date, but no obvious segregation between treated and control animals was observed within the temporal segregation pattern. Temporal variation is something which is not entirely unexpected, as the horses were outside grazing on general pasture. Therefore they were not restricted in terms of the choice of their diet, and the composition of the plant material would almost certainly be influenced by weather

B

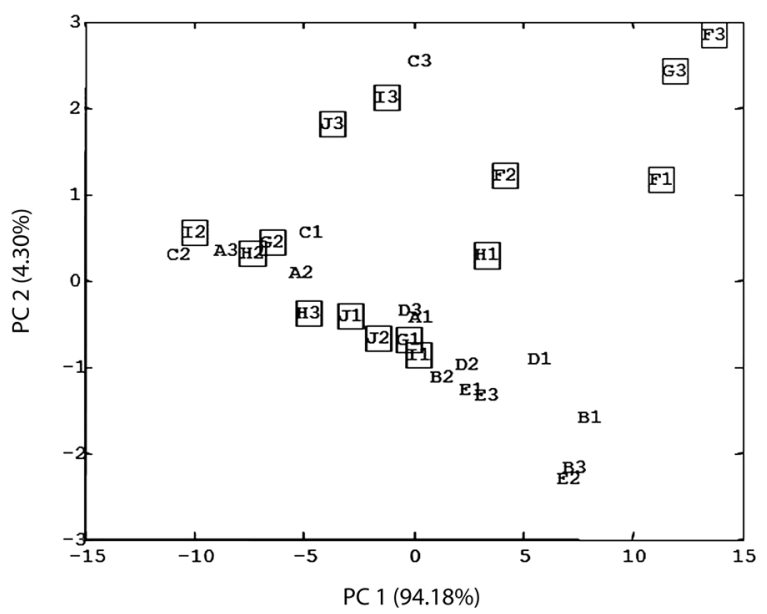

Fig. 2. Principal Component Analysis plot of principal components 1 and 2 from FT-IR data. Samples are coded by animal with a combination of letters and numbers, with control animals (no worming treatment) denoted by the letters A-E and those which were wormed denoted by the letters F-J. For sampling period, samples collected immediately before worming (day 0 ) are denoted by the number 1 , those collected two days after worming (day 2) are denoted by the number 2, and those collected fourteen days after worming (day 14) are denoted by the number 3. In Fig. 2A those collected immediately before worming (day 0 ) are shown without a surrounding circle or square, those collected two days after worming (day 2) are shown in circles, and those collected fourteen days after worming (day 14) are shown in squares. In Fig. 2B those which had not been wormed are without a surrounding square, whilst those which had been wormed are shown in squares. 
conditions. During the sampling period maximum daily temperatures ranged from $14-21^{\circ} \mathrm{C}$, minimum temperatures ranged from $4-12^{\circ} \mathrm{C}$, and daily rainfall ranged from $0-15$ $\mathrm{mm}$, although it is worth noting that there was $88 \mathrm{~mm}$ of rainfall in West Wales on the day immediately prior to collection (day-1) (http://www.weatheronline.co.uk). Given this range of climatic conditions, it is highly likely that there would be chemical changes (e.g., sugar composition) in the plants. In turn these differences could have an influence on the bacteria capable of utilising the plants and therefore able to proliferate on a day-to-day basis.

In addition, based on FT-IR data, no obvious difference in metabolite patterns could be detected. While FT-IR is a measure of the abundance of bonds, rather than individual molecules present, there is a relationship between the two, and the technique has been used to provide a good indication of the range of metabolites from digested plant material [13]. Thus, although T-RFLP data (Fig. 1) suggest temporal differences in the bacteria present, the differences do not appear to impact on the final metabolites (Fig. 2) available to the animal.

While there are limitations associated with the current work due to the fact that faecal samples were used to give an indication of the microbes and metabolites in the hindgut. The samples were collected immediately after being voided and so provided a non-invasive measure of microbes and metabolites which were recently within the hindguts of the horses. Moreover, given the non-invasive nature of the work, the present study provides an indication of what could be carried out with horses owned as companion or competitive animals, rather than just horses which have been designated as experimental animals.

While it was anticipated that the worming agent was unlikely to affect the composition of the microbial community, it was unknown what effects the removal of worms would have on the numbers and relative abundance of both these microbes and the metabolites they produce. We conclude that the current work suggests that treatment with this specific worming agent does not lead to a change in either the bacterial or protozoal populations. In addition no change was detected in the major chemical bonds present, suggesting that it was not possible to detect a change in the major metabolites being produced. In turn this suggests that the only effect to be had from treatment with this worming agent is its intended purpose of killing intestinal worms.

\section{Acknowledgments}

Laura Crotch-Harvey was funded by an Access to Masters Scholarship as part of the European Social Fund (ESF) through the European Union's Convergence programme administered by the Welsh Government.

\section{References}

1. Allison, K., Taylor, N.M., Wilsmore, A.J., and Garforth, C. 2011. Equine anthelmintics: survey of the patterns of use, beliefs and attitudes among horse owners in the UK. Vet. Rec. 168: 483-487. [Medline] [CrossRef]

2. Blackhall, W.J., Kuzmina, T., and von Samson-Himmelstjerna, G. 2011. $\beta$-Tubulin genotypes in six species of cyathostomins from anthelmintic-naive Przewalski and benzimidazole-resistant brood horses in Ukraine. Parasitol. Res. 109: 1199-1203. [Medline] [CrossRef]

3. Edmunds, J.L., Worgan, H.J., Dougal, K., Girdwood, S.E., Douglas, J.L., and McEwan, N.R. 2016. In vitro analysis of the effect of supplementation with activated charcoal on the equine hindgut. J. Equine Sci. 27: 49-55. [Medline] [CrossRef]

4. Geary, T.G., Hosking, B.C., Skuce, P.J., von SamsonHimmelstjerna, G., Maeder, S., Holdsworth, P., Pomroy, W., and Vercruysse, J. 2012. World Association for the Advancement of Veterinary Parasitology (W.A.A.V.P.) Guideline: anthelmintic combination products targeting nematode infections of ruminants and horses. Vet. Parasitol. 190: 306-316. [CrossRef]

5. Ike, K., Nuruki, R., Imai, S., and Ishii, T. 1983. Composition of intestinal ciliates and bacteria excreted in feces of the race-horse. Nippon Juigaku Zasshi 45: 157-163. [Medline] [CrossRef]

6. Kaplan, R.M., and Nielsen, M.K. 2010. An evidence-based approach to equine parasite control; it ain't the 60s anymore. Equine Vet. Educ. 22: 306-316. [CrossRef]

7. Nielsen, M.K., Baptiste, K.E., Tolliver, S.C., Collins, S.S., and Lyons, E.T. 2010. Analysis of multiyear studies in horses in Kentucky to ascertain whether counts of eggs and larvae per gram of feces are reliable indicators of numbers of strongyles and ascarids present. Vet. Parasitol. 174: 77-84. [Medline] [CrossRef]

8. Nielsen, M.K., Fritzen, B., Duncan, J.L., Guillot, J., Eysker, M., Dorchies, P., Laugier, C., Beugnet, F., Meana, A., Lussot-Kervern, I., and von Samson-Himmelstjerna, G. 2010. Practical aspects of equine parasite control: a review based upon a workshop discussion consensus. Equine Vet. J. 42: 460-468. [Medline] [CrossRef]

9. Relf, V.E., Morgan, E.R., Hodgkinson, J.E., and Matthews, J.B. 2012. A questionnaire study on parasite control practices on UK breeding Thoroughbred studs. Equine Vet. J. 44: 466-471. [Medline] [CrossRef]

10. Relf, V.E., Morgan, E.R., Hodgkinson, J.E., and Matthews, J.B. 2013. Helminth egg excretion with regard to age, gender and management practices on UK Thoroughbred studs. Parasitology 140: 641-652. [Medline] [CrossRef]

11. Traversa, D., Castagna, G., von Samson-Himmelstjerna, G., Meloni, S., Bartolini, R., Geurden, T., Pearce, M.C., Woringer, E., Besognet, B., Milillo, P., and D'Espois, M. 2012. Efficacy of major anthelmintics against horse 
cyathostomins in France. Vet. Parasitol. 188: 294-300. [Medline] [CrossRef]

12. Wood, E.L.D., Matthews, J.B., Stephenson, S., Slote, M., and Nussey, D.H. 2013. Variation in fecal egg counts in horses managed for conservation purposes: individual egg shedding consistency, age effects and seasonal variation. Parasitology 140: 115-128. [Medline] [CrossRef]
13. Zhang, X., and Yu, P. 2012. Differentiation of mixtures of co-product blend with barley grain based on Fourier transform infrared attenuated total reflection molecular spectroscopy: carbohydrate molecular spectral profiles and nutritive characteristics in dairy cattle. J. Dairy Sci. 95: 6624-6634. [Medline] [CrossRef] 